\title{
Recombinant Human Factor IX Produced from Transgenic Porcine Milk
}

\author{
Meng-Hwan Lee, Yin-Shen Lin, Ching-Fu Tu, and Chon-Ho Yen \\ Division of Animal Technology, Animal Technology Laboratories, Agricultural Technology Research Institute, \\ No. 52 Kedong 2 Road, Zhunan Township, Miaoli County 350, Taiwan
}

Correspondence should be addressed to Chon-Ho Yen; chy01@mail.atit.org.tw

Received 5 February 2014; Revised 15 April 2014; Accepted 21 April 2014; Published 18 May 2014

Academic Editor: Saulius Butenas

Copyright (C) 2014 Meng-Hwan Lee et al. This is an open access article distributed under the Creative Commons Attribution License, which permits unrestricted use, distribution, and reproduction in any medium, provided the original work is properly cited.

\begin{abstract}
Production of biopharmaceuticals from transgenic animal milk is a cost-effective method for highly complex proteins that cannot be efficiently produced using conventional systems such as microorganisms or animal cells. Yields of recombinant human factor IX (rhFIX) produced from transgenic porcine milk under the control of the bovine $\alpha$-lactalbumin promoter reached $0.25 \mathrm{mg} / \mathrm{mL}$. The rhFIX protein was purified from transgenic porcine milk using a three-column purification scheme after a precipitation step to remove casein. The purified protein had high specific activity and a low ratio of the active form (FIXa). The purified rhFIX had 11.9 $\gamma$-carboxyglutamic acid (Gla) residues/mol protein, which approached full occupancy of the 12 potential sites in the Gla domain. The rhFIX was shown to have a higher isoelectric point and lower sialic acid content than plasma-derived FIX (pdFIX). The rhFIX had the same $N$-glycosylation sites and phosphorylation sites as pdFIX, but had a higher specific activity. These results suggest that rhFIX produced from porcine milk is physiologically active and they support the use of transgenic animals as bioreactors for industrial scale production in milk.
\end{abstract}

\section{Introduction}

Hemophilia B (Christmas disease) is the second most common type of hemophilia and is caused by deficiency of factor IX (FIX), a vitamin K-dependent (VKD) serine protease zymogen (Mr 57,000). FIX has a clearly defined four-domain structure that encompasses a $\gamma$-carboxyglutamic acid (Gla) rich-domain, two epidermal growth factor-like (EGF-like) domains, and a $C$-terminal serine protease domain [1]. Activation of FIX is achieved by the proteolytic cleavage of an activation peptide $(\mathrm{Mr} 11,000)$ by either FXIa or FVIIa-tissue factor [2]. The protein then undergoes extensive posttranslational modification (PTM), including formation of seven disulfide bridges, addition of two $\mathrm{N}$-glycans and six $\mathrm{O}$-glycans, one phosphorylation, one sulfation, one hydroxylation, and up to twelve $\gamma$-carboxyglutamic acids [1]. Recombinant human FIX is currently produced from transgenic Chinese hamster ovary (CHO) cells and is commercially available as BeneFIX [3]. This is structurally and functionally similar to plasma-derived FIX (pdFIX), but with minor differences in posttranslational modification, such as sulfation, phosphorylation, and glycosylation $[4,5]$.

The feasibility of using transgenic animals as a source of recombinant proteins has been demonstrated for over two decades [6] and recombinant proteins have been produced and secreted in body fluids such as milk, blood, urine, and semen [7]. The mammary gland has been used successfully as a bioreactor to produce a variety of human proteins because milk is easily collected in large volumes and the gland is equipped to perform all of the necessary complex posttranslational modifications [8]. Both recombinant human antithrombin III (ATryn, GTC Biotherapeutics Inc.) expressed in goat milk and recombinant $\mathrm{Cl}$ esterase inhibitor (Ruconest, Pharming Group NV) expressed in rabbit milk have received marketing authorization $[9,10]$.

Bioactive rhFIX was first produced from transgenic sheep, but was only expressed at $25 \mathrm{ng} / \mathrm{mL}$ under the control of the mammary-specific $\beta$-lactoglobulin promoter [11]. 
The rhFIX produced from transgenic porcine milk was increased to $2 \sim 3 \mathrm{~g} / \mathrm{L}$ and contained about $70-140 \mathrm{U} / \mathrm{mL}$ after introduction of a fused mouse whey acidic protein (WAP) promoter. However, only about $10 \%$ of the rhFIX was biologically active. Furthermore, high expression was only obtained during the early stage of the lactation period $[12,13]$. In 1998, Wu developed the double-transgenic pig to produce both rhFIX and porcine lactoferrin from milk under the control of the bovine $\alpha$-lactalbumin ( $\alpha \mathrm{LA})$ promoter [14]. The expression of rhFIX in transgenic milk (tgFIX) reached $0.25 \mathrm{~g} / \mathrm{L}$ during the entire lactation period. However, the activated form of FIX (FIXa), a major thrombogenic trigger, was also found in the transgenic porcine milk. The aim of this work was to purify and characterize the posttranslational modifications of tgFIX (rhFIXfrom transgenic porcine milk).

\section{Materials and Methods}

2.1. Collection of Transgenic Porcine Milk. Double-transgenic pigs carrying the human FIX [15] and porcine lactoferrin [16] genes driven by the bovine $\alpha$-lactalbumin ( $\alpha \mathrm{LA})$ promoter were obtained from the National Taiwan University, Taipei, Taiwan [17]. Oxytocin (20 IU) is given via sow ear vein injection through a winged infusion set (Meditop Corporation; SLG, Malaysia) to induce lactating from day 7 to day 30 after parturition. During milk collection, the sows have $8-10$ piglets suckling concurrently and the sow requires stimulation from piglets to maintain the lactation capability. Two sows were provided about $900 \mathrm{~mL}$ milk in a collection procedure. The collected milk was defatted by centrifugation at $10,000 \mathrm{~g}$ for $20 \mathrm{~min}$ and stored at $-80^{\circ} \mathrm{C}$ until purification.

2.2. Purification of tgFIX from Porcine Milk. The skim milk was mixed with $1 / 9$ volume of $1 \mathrm{M}$ sodium phosphate buffer (pH 5.8). The mixture was divided into aliquots, $50 \mathrm{~mL}$ Falcon Centrifuge Tube, and then frozen at $-80^{\circ} \mathrm{C}$ until completely frozen. The frozen samples $(200 \mathrm{~mL})$ were completely thawed in a refrigerator at $4^{\circ} \mathrm{C}$, followed by centrifugation at $10,000 \mathrm{~g}$ for 10 minutes to remove the precipitated caseins. The supernatant was diluted with a 1.5-fold volume of buffer A (50 mM Tris- $\mathrm{HCl}, \mathrm{pH}$ 7.2) for subsequent purification by chromatography. The diluted fraction $(409 \mathrm{~mL})$ was applied to a Q-Sepharose column $(2.6 \mathrm{~cm} \times 15 \mathrm{~cm})$. After the column was washed with $240 \mathrm{~mL}$ buffer A, the enzyme was eluted with $0.3 \mathrm{M} \mathrm{NaCl}$ in buffer A. The enzyme solution was then applied to a heparin-Sepharose column $(1.6 \mathrm{~cm} \times 15 \mathrm{~cm})$, which was preequilibrated with buffer A containing $0.2 \mathrm{M}$ $\mathrm{NaCl}$. The active fractions were eluted with $0.3 \mathrm{M} \mathrm{NaCl}$ in buffer A. The pooled active fractions were applied to a Concanavalin A column $(1.6 \mathrm{~cm} \times 10 \mathrm{~cm})$, which was preequilibrated with $40 \mathrm{mM}$ Tris- $\mathrm{HCl}$ buffer, $\mathrm{pH} 7.2$ containing $1 \mathrm{M} \mathrm{NaCl}, 2 \mathrm{mM} \mathrm{MnCl}$, and $2 \mathrm{mM} \mathrm{CaCl}_{2}$. The enzyme was eluted with $20 \mathrm{mM}$ Tris- $\mathrm{HCl}$ buffer, $\mathrm{pH} 7.2$ containing $0.5 \mathrm{M}$ $\mathrm{NaCl}$, and $0.2 \mathrm{M}$ methyl $\alpha$-D-mannopyranoside. The active fractions were pooled and stored at $-20^{\circ} \mathrm{C}$.

2.3. FIX Activity Assay. FIX activity was measured using the activated partial thromboplastin time (APTT) assay using the STA Compact analyzer (Diagnostica Stago, Inc., Asnieres, France) according to the manufacturer's protocol. Factor IXdeficient plasma was used as substrate. Factor IX activity was determined against a World Health Organization (WHO) International Standard in the range of $0.14 \mathrm{IU}$ to $1.6 \mathrm{IU}$. The WHO International Standard (the 4th International Standard for FIX Concentrate) was purchased from The National Institute for Biological Standards and Control (NIBSC, Hertfordshire, UK). One unit of FIX activity was defined as the activity of FIX in $1 \mathrm{~mL}$ of pooled human plasma.

2.4. FIXa Activity Assay. Activated Factor IX (FIXa) activity was measured using a chromogenic assay (Hyphen BioMed, Neuville-Sur-Oise, France) according to the manufacturer's instructions using the manual end-point method.

2.5. Protein Concentration Determination. Protein concentration was determined using the Bradford method with bovine serum albumin as the standard.

2.6. Nonreducing SDS-PAGE and IEF. Electrophoresis was performed using a 10\% nonreducing SDS-polyacrylamide gel electrophoresis system (Invitrogen, Carlsbad, CA). Isoelectric focusing (IEF) was performed using Invitrogen $\mathrm{pH} 3-$ 7 gels according to the manufacturer's instructions (Invitrogen).

\subsection{Analysis of Protein Posttranslational Modifications}

2.7.1. Oligosaccharide Determination. Oligosaccharides of $\operatorname{tgFIX}(1 \mathrm{mg})$ were released after overnight digestion at $37^{\circ} \mathrm{C}$ with PNGase F (1000 U/mL, Roche, Mannheim, Germany) in $20 \mathrm{mM}$ ammonium bicarbonate buffer; $\mathrm{pH}$ 8.0. Oligosaccharides were analyzed on a CarboPac PA-100 column $(25 \mathrm{~cm} \times$ $4.6 \mathrm{~mm}, 5 \mu \mathrm{m}$ ) using a Dionex HPAEC-PAD system (Dionex, Sunnyvale, CA). Bovine fetuin was used as a reference material.

2.7.2. Monosaccharide Determination. The total carbohydrate content of tgFIX was determined by the orcinol-sulfuric acid method. Monosaccharide composition was analyzed by gas chromatography-mass spectrometry using a HewlettPackard model 6890 gas chromatograph, connected to a Hewlett-Packard 5973 mass-selective detector [18].

2.7.3. Sialic Acid Determination. The sialic acid content released from tgFIX was determined using the Sialic Acid (NANA) Assay Kit (BioVision, Mountain View, CA).

2.7.4. Gla Determination. $\gamma$-Carboxyglutamic acid (Gla) content was determined by amino acid analysis as described by Price [19]. One mg of protein was subjected to alkaline hydrolysis in $2 \mathrm{~N} \mathrm{KOH}$ for $48 \mathrm{~h}$ at $110^{\circ} \mathrm{C}$. Hydrolyzed amino acids were filtrated through a $0.2 \mu \mathrm{m}$ filter to remove precipitate. Supernatants were separated by high performance liquid chromatography on an AminoPac PA10 strong anion-exchange column with pulsed amperometric detector 
TABLE 1: Summary of a representative purification of tg-FIX from transgenic porcine milk.

\begin{tabular}{|c|c|c|c|c|c|c|c|}
\hline Step & Volume (mL) & Total protein (mg) & Total activity (U) & $\begin{array}{c}\text { Specific activity } \\
(\mathrm{U} / \mathrm{mg})\end{array}$ & $\begin{array}{l}\text { Purification } \\
\text { (fold) }\end{array}$ & Yield (\%) & $\begin{array}{c}\text { FIXa/FIX } \\
(\%)\end{array}$ \\
\hline Whey & 409 & 11342 & 34026 & 3 & 1 & 100 & 19 \\
\hline Q-Sepharose & 100 & 211 & 25531 & 121 & 40 & 75 & 18 \\
\hline Heparin-Sepharose & 23 & 42 & 10752 & 256 & 85 & 32 & 11 \\
\hline Concanavalin A-Sepharose & 20 & 12 & 3516 & 293 & 98 & 10 & 1 \\
\hline
\end{tabular}

(Dionex, Sunnyvale, CA) using an elution buffer of $1 \mathrm{M}$ sodium citrate. Purified $\gamma$-carboxyglutamic acid and aspartic acid (Sigma-Aldrich) were used as standards, and samples were compared with a control sample (pdFIX, Enzyme Research Labs, South Bend, IN). Determinations were performed in duplicate, and results are reported as an average.

2.7.5. Protein Phosphorylation Determination. Protein phosphorylation was measured by the Phosphoprotein Phosphate Estimation Assay Kit (Pierce Biotechnology, Rockford, IL). The protein samples were incubated in $1 \mathrm{~N} \mathrm{NaOH}$ at $65^{\circ} \mathrm{C}$ for 30 minutes to release phosphate. After neutralization with $\mathrm{HCl}$, a mixture of malachite green and acidified ammonium molybdate was added to form a complex of phosphomolybdate and malachite green. The absorbance at $630 \mathrm{~nm}$ was read and the amount of phosphate was determined from a phosvitin standard curve.

2.7.6. Protein Sulfation Determination. The tyrosine $O$-sulfate in tgFIX was determined by DABS-Cl method as described previously [20]. Activation peptide of tgFIX was digested with trypsin and purified by reverse phase HPLC [21]. Subsequently, $20 \mathrm{pmol} / \mu \mathrm{L}$ activation peptide of tgFIX was digested with $0.02 \mu \mathrm{g} / \mu \mathrm{L}$ carboxypeptidase $\mathrm{Y}$ in $25 \mathrm{mM}$ sodium citrate buffer, $\mathrm{pH}$ 6.0, at room temperature. Following digestion, $10 \mu \mathrm{L}$ mixture was added to $40 \mu \mathrm{L} 0.2 \mathrm{M}$ sodium bicarbonate buffer at $\mathrm{pH} 9$ and $100 \mu \mathrm{L}$ DABS-Cl $(1.3 \mathrm{mg} / \mathrm{mL}$ in acetone) was added to produce DABS-amino acids. Reaction mixtures were incubated at $70^{\circ} \mathrm{C}$ for $10 \mathrm{~min}$, dried in a vacuum, and redissolved in $70 \%$ ethanol for analysis using RP-HPLC.

2.8. Peptide Mapping. Transgenic FIX $(157.5 \mu \mathrm{g})$ was reduced with $2 \mathrm{mM}$ dithiothreitol (Sigma) at $56^{\circ} \mathrm{C}$ for $1 \mathrm{~h}$ and alkylated for $1.5 \mathrm{~h}$ at room temperature (in the dark) with $5 \mathrm{mM}$ iodoacetamide (Sigma). The sample was diluted with $50 \mathrm{mM}$ ammonium bicarbonate and then $2 \mu \mathrm{g}$ of trypsin was added and incubated for $18 \mathrm{~h}$ at $37^{\circ} \mathrm{C}$. After tryptic digestion, the sample was deglycosylated overnight at $37^{\circ} \mathrm{C}$ either with or without PNGase F. The peptide fragments were analyzed by HPLC (Waters, Milford, MA) with a reversed phase column (Biobasic-18, $5 \mu \mathrm{m}, 300 \AA$, $4.6 \mathrm{~mm} \times 250 \mathrm{~mm}$, Thermo Electron). The eluted fractions were collected manually according to the absorbance at $214 \mathrm{~nm}$. Collected samples were dried by SpeedVac and then subjected to analysis by the CapLC System (Waters) using a capillary column $(75 \mu \mathrm{m}$ i.d., $10 \mathrm{~cm}$ in length, MST, Taiwan) with a linear gradient of $30 \%$ to $80 \%$ acetonitrile containing $0.1 \%$ formic acid over $40 \mathrm{~min}$. The separated peptides were online analyzed under positive

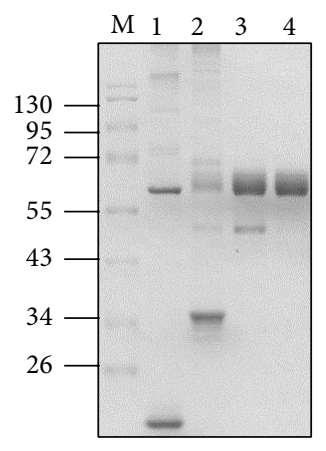

(a)

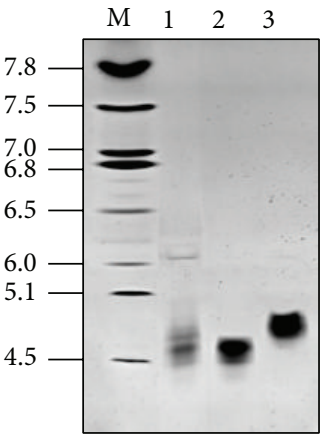

(b)
FIGURE 1: Electrophoretic analysis of rhFIX from transgenic porcine milk. (a) Nonreducing SDS-PAGE analysis. All lanes contain $10 \mu \mathrm{g}$ of protein. Lane M: molecular mass markers, Lane 1: whey. Lane 2: Q-Sepharose. Lane 3: heparin-Sepharose. Lane 4: Con A-Sepharose. (b) Isoelectric focusing (IEF) analysis. IEF was performed using Invitrogen $\mathrm{pH}$ 3-7 gels. Proteins were detected with Coomassie blue stain. Lane M: pI markers, Lane 1: plasma-derived FIX (pdFIX), Lane 2: FIX recombinantly produced from CHO cells (CHO-FIX), Lane 3: rhFIX purified from transgenic porcine milk (tgFIX).

survey scan mode on an ESI-Q-TOF (Micromass, Manchester, UK) instrument. All MS/MS spectra were processed using Mascot Distiller (Matrix Science, London, UK), and the resulting PKL files were searched using the Mascot search engine v2.2 (Matrix Science).

\section{Results}

3.1. Purification of tgFIX. The concentration of tgFIX in the raw milk of transgenic pigs was approximately $0.250 \mathrm{~g} / \mathrm{L}$. The results of the tgFIX purification from $450 \mathrm{~mL}$ skim milk are summarized in Table 1 . The purified rhFIX had a specific activity of $293 \mathrm{U} / \mathrm{mg}$. The ratio of FIXa/FIX was decreased to $1 \%$. The final product appeared to be homogenous after analysis by nonreducing SDS-PAGE (Figure 1(a)). The $N$-terminal sequence was determined by Edman degradation method, and the sequence was found to be YNSGKLXXFVGG, which is identical to pdFIX.

3.2. Molecular Weight and Isoelectric Point. The apparent molecular mass of the purified enzyme was $57,000 \mathrm{Da}$ as determined by nonreducing SDS-PAGE (Figure 1(a)). These results suggest that the enzyme is composed of a single polypeptide chain. The isoelectric point was estimated to be 4.8, which is higher than pdFIX and CHO-FIX (Figure 1(b)). 
TABLE 2: Monosaccharide content of tgFIX purified from transgenic porcine milk.

\begin{tabular}{lc}
\hline Monosaccharide & $\mathrm{mol} / \mathrm{mol} \operatorname{tgFIX}$ \\
\hline$N$-Acetylgalactosamine & 5.16 \\
$N$-Acetylglucosamine & 14.12 \\
$N$-Acetylneuraminic acid & 4.26 \\
Fucose & 1.25 \\
Galactose & 11.88 \\
Glucose & 1.41 \\
Mannose & 5.73 \\
Xylose & 4.32 \\
\hline
\end{tabular}

TABLE 3: Sialic acid content of FIX.

\begin{tabular}{lc}
\hline Sialic acid & $\mathrm{mol} / \mathrm{mol} \mathrm{FIX}$ \\
\hline tgFIX & $5.10 \pm 0.04$ \\
pdFIX & $8.69 \pm 0.12$ \\
CHO-FIX & $6.77 \pm 0.20$ \\
\hline
\end{tabular}

3.3. Monosaccharide and Sialic Acid Content. The total carbohydrate content of tgFIX was $7.86 \pm 0.27 \%$ as determined by the orcinol-sulfuric acid method. The monosaccharide composition in tgFIX is given in Table 2. N-Glycolylneuraminic acid (NeuGc) was not found in the tgFIX oligosaccharide. The sialic acid content of FIX from three different sources was shown in Table 3. tgFIX contains 5.10 sialic acid in each molecule less than the one derived from plasma or from $\mathrm{CHO}$ cell. The difference of isoelectric point may be attributed to different sialic acid contents in these products (Table 3).

3.4. N-Linked Oligosaccharide. In order to investigate the sialylation and complexity of glycans, the $N$-linked oligosaccharides from tgFIX were released with PNGase F and analyzed using the HPAEC-PAD system (Figure 2). Bovine fetuin, a well-characterized glycoprotein, was used as the standard in this study. Comparison of the $\mathrm{N}$-glycan retention times indicated that the $\mathrm{N}$-glycans derived from tgFIX contained neutral, monosialylated, and disialylated oligosaccharides (Figure 2(a)). In contrast, di-, tri-, and tetrasialylated glycans were predominant in pdFIX (Figure 2(b)).

3.5. Gla Content. The N-terminal Gla domain of FIX contains 12 potential sites for $\gamma$-carboxylated glutamic acid residues. In this study, tgFIX had 11.9 Gla residues/mol proteins, which was similar to the pdFIX that was analyzed as a control.

3.6. Protein Phosphorylation and Sulfation. A phosphorylated serine residue at position 158 of rhFIX has been shown to be associated with a lower in vivo recovery after infusion into hemophilia B patients [5]. Transgenic FIX had 0.36 phosphorus/mol proteins determined by Phosphoprotein Phosphate Estimation Kit. In contrast, pdFIX can contain up to 0.89 phosphorus/mol proteins.

The phosphorylation site on Ser158 of tgFIX was determined by digestion with trypsin and PNGase F; then the

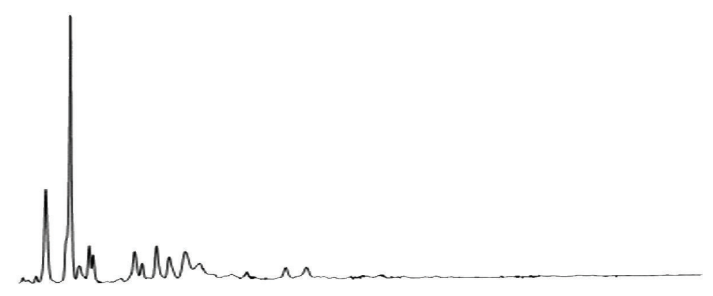

(a)

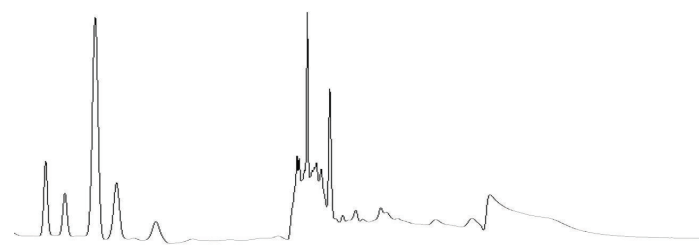

(b)

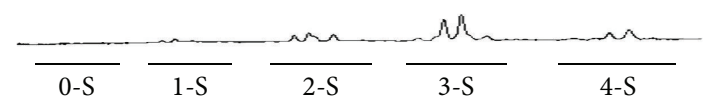

(c)

FIGURE 2: $N$-Glycans profile of (a) tgFIX, (b) pdFIX, and (c) bovine fetuin analyzed using HPAEC-PAD. Oligosaccharides were analyzed by the HPAEC-PAD system. The labels $0-S, 1-S, 2-S, 3-S$, and $4-S$ indicate mono-, di-, tri-, and tetra-sialylated oligosaccharide groups, respectively.

peptides were analyzed by MALDI-TOF MS. The MALDITOF MS spectrum showed two peaks with the observed $\mathrm{m} / \mathrm{z} 3942.6$ and 4022.6 that corresponded to the calculated MW of deglycosylation activation peptide of tgFIX without and with phosphorylation, respectively. The $\mathrm{m} / \mathrm{z} 4022.6$ peak was selected for MS/MS analysis and gained the amino acid sequence identical to deglycosylation activation peptide of tgFIX with a phosphorylation modified on Ser158 residue (data not shown).

The sulfation of Tyr residue on activation peptide was not detectable by using amino acid analysis by using DABS-Cl.

3.7. Peptide Mapping. For the determination of protein deamidation and oxidation, the tgFIX sample was treated by trypsin digestion in the presence or absence of PNGase F. The peptides were then subjected to reversed-phase HPLC separation. Each peak was collected manually and then analyzed by LC-MS/MS followed by a Mascot database search for peptide identification (Figure 3 ). The peptide identification details are summarized in Table 4. Some peptides were observed in adjacent HPLC fractions because of peak tailing and possible random error caused from manual collection. Overall, $80 \%$ sequence coverage of FIX was obtained. Only the T18 peptide was observed in a sample which had undergone trypsin plus PNGase F treatment. In addition, two deamidations were found in the T18 peptide. These data suggests that Asn157 and Asn167 were originally Nglycosylated. The tgFIX sample showed evidence of deamidation at Asn92, Asn199, and Asn347. Most of the T35 peptide fragments were found to be oxidatively modified at Met348. 
TABle 4: Peptide matching of tgFIX digested by trypsin plus PNGase F. Fractions were collected manually from HPLC separation. This represents data from the same experiment as shown in Figure 3. The peptide identities suggested by LC-MS/MS analysis are listed. Those fractions in which no peptide was identified are removed from the list.

\begin{tabular}{|c|c|c|c|c|c|}
\hline $\begin{array}{l}\text { Fraction } \\
\text { number }\end{array}$ & Time & $\begin{array}{l}\text { Peptide } \\
\text { number }\end{array}$ & Position & Observed $m / z$ & Match peptides \\
\hline 1 & $35.1 \sim 35.8$ & T16 & $135-142$ & 418.1808 & VSVSQTSK \\
\hline 5 & $38.8 \sim 40.2$ & T11 & $95-100$ & 871.442 & CEQFCK \\
\hline 6 & $42.4 \sim 43.1$ & $\mathrm{~T} 13$ & $107-116$ & 615.7483 & VVCSCTEGYR \\
\hline 7 & $48.0 \sim 48.8$ & $\mathrm{~T} 12-\mathrm{T} 13$ & $101-116$ & 620.5777 & NSADNKVVCSCTEGYR \\
\hline \multirow{2}{*}{8} & \multirow{2}{*}{$50.2 \sim 51.2$} & $\mathrm{~T} 38$ & $395-400$ & 744.471 & YGIYTK \\
\hline & & T37-T38 & $393-400$ & 465.2822 & GKYGIYTK \\
\hline 10 & $54.0 \sim 54.8$ & $\mathrm{~T} 25$ & $253-265$ & 752.9462 & IIPHHNYNAAINK \\
\hline 11 & $57.0 \sim 57.8$ & T9-T10 & $81-94$ & 565.2617 & NCELDVTCNIKNGR + Deamidated (NQ) \\
\hline 12 & $59.4 \sim 60.2$ & T22-T23 & $229-248$ & 580.8007 & ITVVAGEHNIEETEHTEQKR \\
\hline 13 & $60.3 \sim 61.2$ & T9 & $81-91$ & 683.3281 & NCELDVTCNIK \\
\hline 14 & $62.8 \sim 63.8$ & $\mathrm{~T} 20$ & $202-214$ & 698.3452 & VDAFCGGSIVNEK \\
\hline 15 & $63.9 \sim 64.6$ & T6 & $38-43$ & 406.2174 & TTEFWK \\
\hline \multirow{2}{*}{16} & \multirow{2}{*}{$64.8 \sim 65.8$} & T40-T41 & $404-411$ & 540.3281 & YVNWIKEK \\
\hline & & $\mathrm{T} 15$ & $123-134$ & 688.851 & SCEPAVPFPCGR \\
\hline 17 & $67.4 \sim 68.0$ & $\mathrm{~T} 28$ & $302-312$ & 586.8006 & FGSGYVSGWGR \\
\hline 18 & $68.2 \sim 68.8$ & $\mathrm{~T} 40$ & $404-409$ & 411.7751 & YVNWIK \\
\hline 19 & $70.4 \sim 71.4$ & $\mathrm{~T} 21$ & $215-228$ & 785.9102 & WIVTAAHCVETGVK \\
\hline 20 & $71.6 \sim 72.6$ & $\mathrm{~T} 40-\mathrm{T} 43$ & $404-415$ & 761.9668 & YVNWIKEKTKLT \\
\hline 21 & $80.8 \sim 81.4$ & T35 & $342-358$ & 679.6353 & FTIYNNMFCAGFHEGGR + Oxidation (M) \\
\hline \multirow{2}{*}{22} & \multirow{2}{*}{$81.4 \sim 82.8$} & T30-T31 & $317-327$ & 638.3962 & GRSALVLQYLR \\
\hline & & T35 & $342-358$ & 679.6486 & FTIYNNMFCAGFHEGGR + Oxidation (M) \\
\hline 24 & $82.8 \sim 83.4$ & T35 & $342-358$ & 679.6478 & FTIYNNMFCAGFHEGGR + Oxidation (M) \\
\hline 25 & $83.4 \sim 84.0$ & $\mathrm{~T} 31$ & $319-327$ & 531.8453 & SALVLQYLR \\
\hline \multirow{3}{*}{26} & \multirow{3}{*}{$84.1 \sim 85.0$} & T31 & $319-327$ & 531.8246 & SALVLQYLR \\
\hline & & T35 & $342-358$ & 674.6462 & FTIYNNMFCAGFHEGGR + Deamidated (NQ) \\
\hline & & T34-T35 & $339-358$ & 779.7193 & STKFTIYNNMFCAGFHEGGR \\
\hline \multirow{4}{*}{27} & \multirow{4}{*}{$85.4 \sim 86.2$} & $\mathrm{~T} 35$ & $342-358$ & 1010.9647 & FTIYNNMFCAGFHEGGR \\
\hline & & $\mathrm{T} 35$ & $342-358$ & 679.6509 & FTIYNNMFCAGFHEGGR + Oxidation (M) \\
\hline & & $\mathrm{T} 8$ & $64-80$ & 1062.4471 & DDINSYECWCPFGFEGK \\
\hline & & T34-T35 & $339-358$ & 589.0386 & STKFTIYNNMFCAGFHEGGR + Oxidation (M) \\
\hline \multirow{2}{*}{28} & \multirow{2}{*}{$86.4 \sim 87.6$} & T35 & $342-358$ & 1010.9542 & FTIYNNMFCAGFHEGGR \\
\hline & & T35 & $342-358$ & 679.6524 & FTIYNNMFCAGFHEGGR + Oxidation (M) \\
\hline 29 & $88.6 \sim 89.6$ & $\mathrm{~T} 19$ & $181-201$ & 742.7371 & VVGGEDAKPGQFPWQVVLNGK + Deamidated (NQ) \\
\hline 30 & $90.2 \sim 91.0$ & $\mathrm{~T} 19$ & $181-201$ & 742.3987 & VVGGEDAKPGQFPWQVVLNGK \\
\hline 31 & $92.2 \sim 93.2$ & $\mathrm{~T} 19$ & $181-201$ & 742.7443 & VVGGEDAKPGQFPWQVVLNGK + Deamidated (NQ) \\
\hline 34 & $94.2 \sim 95.2$ & T19-T20 & $181-214$ & 901.2115 & VVGGEDAKPGQFPWQVVLNGKVDAFCGGSIVNEK \\
\hline \multirow{2}{*}{37} & \multirow{2}{*}{$106.0 \sim 107.0$} & T31-T33 & $319-338$ & 781.7831 & SALVLQYLRVPLVDRATCLR \\
\hline & & T26 & $266-293$ & 1076.8988 & YNHDIALLELDEPLVLNSYVTPICIADK \\
\hline 38 & $107.4 \sim 108.2$ & T36-T37 & $359-394$ & 957.4534 & DSCQGDSGGPHVTEVEGTSFLTGIISWGEECAMKGK \\
\hline 39 & $108.4 \sim 109.2$ & T36 & $359-392$ & 1214.5544 & DSCQGDSGGPHVTEVEGTSFLTGIISWGEECAMK \\
\hline 43 & $115.6 \sim 116.6$ & $\mathrm{~T} 18$ & $146-180$ & 1313.9320 & $\begin{array}{c}\text { AEAVFPDVDYVNSTEAETILDNITQSTQSFNDFTR + } 2 \\
\text { Deamidated (NQ) }\end{array}$ \\
\hline
\end{tabular}




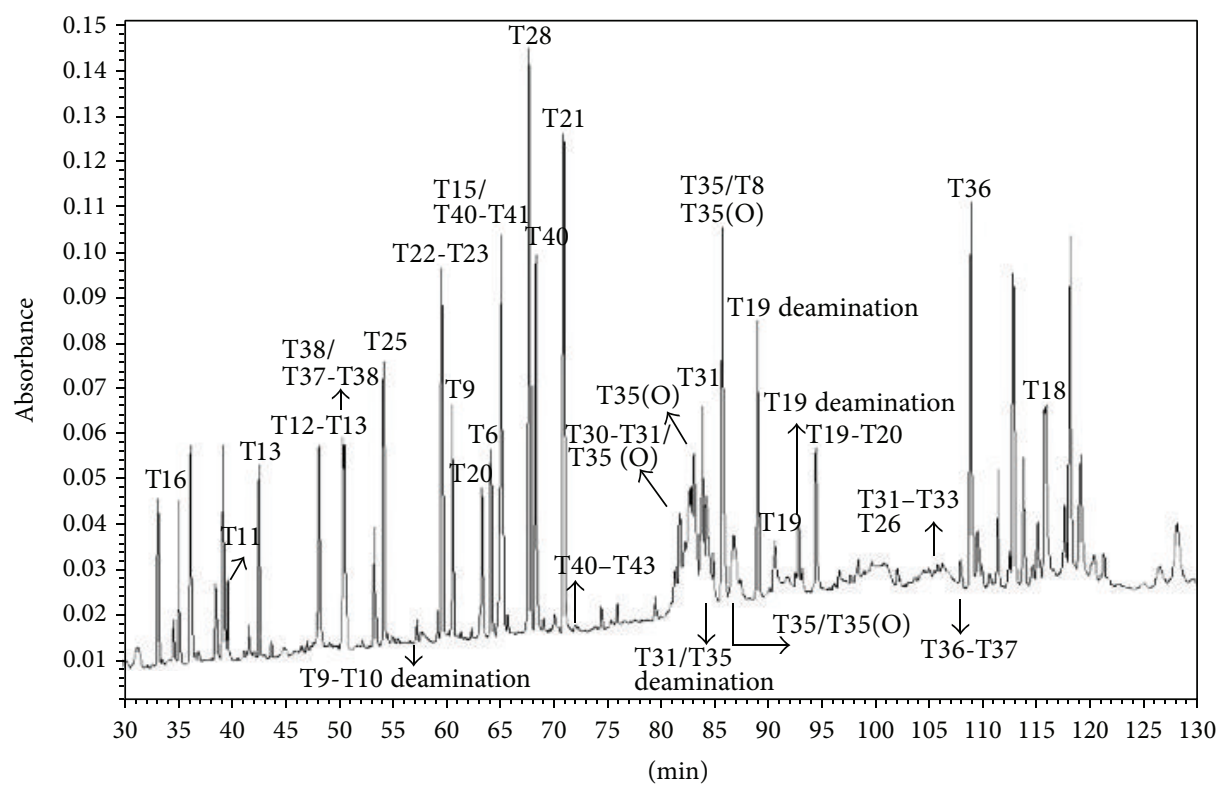

FIGURE 3: HPLC analysis of tgFIX digested by trypsin and PNGase F. Tn denotes the $n$th enzymatic peptide assigned from the $N$-terminal of tgFIX. For example, T1 indicates the first theoretical tryptic peptide from the protein $N$-terminal. $\mathrm{Tn}$ - $\mathrm{Tn}+1 \mathrm{or} \mathrm{Tn}$ - $\mathrm{Tn}+2 \mathrm{indicate}$ peptides resulting from one or two missed cleavages, respectively. The collection time and matched peptide sequence are summarized in Table 4 . Each peptide sequence was supported by MS/MS data and molecular weight match. A Mascot probability-based scoring algorithm was used to evaluate the identification.

The oxidatively modified tgFIX still had high FIX coagulation activity, which suggests that Met348 does not play a key role in FIX coagulation activity.

\section{Discussion}

In our purification scheme, the tgFIX tightly bound to QSepharose than most of whey proteins at $\mathrm{pH} 7.2$, so that the anion exchanger can separate tgFIX from whey proteins. Heparin-Sepharose column is an affinity column specific binding to tgFIX that can remove the impurity to gain tgFIX in high purity. FIXa is the proteolytic product of FIX zymogen. The activation peptide with high glycosylation was released during the proteolytic process. Concanavalin A could specifically bind to glycoprotein. In the Concanavalin A column, the FIXa is easily removed to be only $1 \%$. However, Concanavalin A is toxic to cell [22]. It is necessary to assay the residual concentration of Concanavalin $\mathrm{A}$ in the final product.

Factor IX is synthesized as a precursor polypeptide which requires proteolytic cleavage to remove propeptide for functional activity. In the Chinese hamster ovary (CHO) cells expression system, expression of factor IX, at high levels results in the secretion of a mixture of profactor IX and mature factor IX. In our experiment, the N-terminal sequence of purified tgFIX was found to be YNSGKLXXFVGG, which is identical to pdFIX. In addition, the proper propeptide processing was confirmed by peptide mapping. Our data suggested that the proFIX was removed during the purification scheme. However, the location of proFIX needs more experiments to be clarified.
Factor IX undergoes extensive PTM. The differences in PTM between pdFIX and CHO-FIX products have been extensively researched. Compared with pdFIX, CHO-FIX displays the absence of Ser158 phosphorylation (90\% for pdFIX) [23]. The sulfation site of the activation peptide is largely filled $(>90 \%)$ in pdFIX and largely unfilled in CHOFIX (4-5\%) [24]. The sulfation of Tyr residue on activation peptide of tgFIX was not detectable by amino acid analysis using DABS-Cl. The variability in sulfation and phosphorylation, in particular, is believed to impair in vivo recovery following intravenous infusions of CHO-FIX compared to pdFIX $[23,25]$.

Factor IX is a VKD protein that undergoes carboxylation to the fully $\gamma$-carboxylated mature zymogen, which is then secreted into the circulatory system. Plasma-derived FIX has twelve Gla residues in the $\mathrm{N}$-terminal Gla domain. The Gla domain is responsible for $\mathrm{Ca}^{2+}$ binding, which is necessary for the binding of FIX to membrane phospholipids. Expressiona of recombinant proteins in mammalian cell culture in industry is suitable for the production of proteins with high PTMs; however, inefficient $\gamma$-carboxylation still remains a major problem with regard to VKD proteins [26]. Transgenic animal technology offers an effective expression system for high posttranslationally modified proteins. It was shown that the biologically active subpopulation of rhFIX was only about $10 \%$ in the milk of transgenic pigs that had high expression levels of $2 \sim 3 \mathrm{~g} / \mathrm{L}$ under the control of the WAP promoter. The $\gamma$-carboxylation PTM is rate limiting for recombinant FIX at $0.2 \sim 0.3 \mathrm{~g} / \mathrm{L}$ [13]. In this study, undercarboxylated (inactive) tgFIX protein was still expressed in mammary glands but 
the ratio was reduced to $25-30 \%$ under control of the bovine $\alpha$-LA promoter (data not shown). The undercarboxylated rhFIX in milk could be separated from the fully carboxylated form by Q-Sepharose chromatography resulting in purified tgFIX with 11.9 Gla residues per rhFIX molecule.

FIX can be activated to be FIXa ( $\mathrm{Mr} 46000)$ by FXI and/or FVIIa/tissue factor complex in the presence of calcium and phospholipids [27]. Milk contains both calcium and phospholipid surfaces and a number of proteases that have the potential to degrade foreign proteins but their specific activity does not appear to be high enough to activate FIX to FIXa. In our study, FIXa is activated before the milk collection. The FIX activity was measured using the activated partial thromboplastin time (APTT) assay using the STA Compact analyzer. The high level of FIXa may interfere with the FIX assay. We also measured the FIXa activity by chromogenic assay in each purification scheme. The chromogenic assay is used to determine the activated FIX activity only.

Sialic acid in the terminal of both $\mathrm{N}$-linked and $\mathrm{O}$-linked glycans affects absorption, half-life, and clearance from the serum, as well as the physical, chemical, and immunogenic properties of glycoproteins [28]. Several biopharmaceuticals produced in transgenic animal milk contain a lower content of sialic acid. For example, recombinant human erythropoietin purified from the milk of transgenic pigs has a higher isoelectric point, higher hydrophobicity, and lower sialic acid content than the native protein [29]. $N$-linked glycans of antithrombin from transgenic goat milk [30] and lactoferrin from transgenic cow milk [31] contain less sialic acid than the corresponding glycans found in humans. In addition, tgFIX was shown to have a higher isoelectric point and lower sialic acid content in this study and in a study by Gil et al. [32]. The elimination half-life $\left(t_{1 / 2 \beta}\right)$ of CHO cell-produced rhFIX determined by a conventional monoclonal sandwich ELISA assay was approximately $5.0 \mathrm{~h}$ [33] whereas the $t_{1 / 2 \beta}$ of tgFIX after a single intravenous administration was $9.34 \mathrm{~h} \mathrm{[34].}$

Two main types of sialyl residues are found in biopharmaceuticals produced by mammalian expression systems, for example, $N$-acetyl-neuraminic acid (NeuAc) and $N$-glycolylneuraminic acid (NeuGc). Anti-thrombin III produced by transgenic goats contains two types of sialic acid, NeuAc and NeuGc. Although NeuGc can be found in porcine proteins [32], the tgFIX produced in both this study and a study by Gil et al. [32] contained only NeuAc. NeuGc residues are undetectable in human plasma and are potentially immunogenic to humans. These data demonstrate that the pig is a better choice of animal than goat for the production of recombinant human proteins.

$\mathrm{CHO}$ cells have been successfully used for two decades with similar posttranslational modifications to their native counterparts. The major disadvantages of mammalian cell culture systems are their relatively low production levels and high cost [7]. The lack of availability and affordability of clotting factor concentrates remains a major disappointment to hemophiliacs in the recombinant era. The possible need for factor IX is about $2 \mathrm{~kg}$ per year. Houdebine estimated that four transgenic sows is enough supplied the annual demand of factor IX [7]. However, based on the lower expression level $(0.35 \mathrm{~g} / \mathrm{L})$ and the yield of purification process (assumed to be $10 \%$ ), the minimum herd size of 192 transgenic sows is required in ideal condition for worldwide market. Transgenic animals offer the latest promising alternatives to commercial bioreactors for recombinant protein production. This may open the door for future approval of hemophilia therapies derived from such technology to yield low cost recombinant clotting factors that can be used throughout the developing world.

\section{Conclusion}

In this study, the data clearly demonstrate the expression and characterization of recombinant human FIX by transgenic pigs. The present work demonstrates the potential use of transgenic pigs for the production of tgFIX for the treatment of hemophilia B patients.

\section{Conflict of Interests}

The authors declare that there is no conflict of interests.

\section{Acknowledgments}

This study was supported by Grants (97-EC-17-A-17-R7-0454, 98-EC-17-A-02-04-0454, and 99-EC-17-A-02-04-0454) from the Ministry of Economic Affairs, Taiwan. The authors thank Wen-Dar Fang, Tsang-Kuei Chiu, and Hsueh-Tao Liu, of ATIT Molecular Farm, for providing transgenic porcine milk.

\section{References}

[1] K. Hansson and J. Stenflo, "Post-translational modifications in proteins involved in blood coagulation," Journal of Thrombosis and Haemostasis, vol. 3, no. 12, pp. 2633-2648, 2005.

[2] T. Zögg and H. Brandstetter, "Activation mechanisms of coagulation factor IX," Biological Chemistry, vol. 390, no. 5-6, pp. 391400, 2009.

[3] R. J. Kaufman, L. C. Wasley, B. C. Furie, and C. B. Shoemaker, "Expression, purification, and characterization of recombinant $\gamma$-carboxylated factor IX synthesized in Chinese hamster ovary cells," The Journal of Biological Chemistry, vol. 261, no. 21, pp. 9622-9628, 1986.

[4] S. Harrison, S. Adamson, D. Bonam et al., "The manufacturing process for recombinant factor IX," Seminars in Hematology, vol. 35, no. 2, pp. 4-10, 1998.

[5] G. White, A. Shapiro, M. Ragni et al., "Clinical evaluation of recombinant factor IX," Seminars in Hematology, vol. 35, no. 2, pp. 33-38, 1998.

[6] R. E. Hammer, V. G. Pursel, C. E. Rexroad et al., "Production of transgenic rabbits, sheep and pigs by miroinjection," Nature, vol. 315, no. 6021, pp. 680-683, 1985.

[7] L.-M. Houdebine, "Production of pharmaceutical proteins by transgenic animals," Comparative Immunology, Microbiology and Infectious Diseases, vol. 32, no. 2, pp. 107-121, 2009.

[8] M. K. Dyck, D. Lacroix, F. Pothier, and M.-A. Sirard, "Making recombinant proteins in animals-different systems, different applications," Trends in Biotechnology, vol. 21, no. 9, pp. 394-399, 2003. 
[9] J. Kling, "First US approval for a transgenic animal drug," Nature Biotechnology, vol. 27, no. 4, pp. 302-304, 2009.

[10] J. Kling, "Fresh from the biologic pipeline-2010," Nature Biotechnology, vol. 29, no. 3, pp. 197-200, 2011.

[11] A. J. Clark, H. Bessos, J. O. Bishop et al., "Expression of human anti-hemophilic factor IX in the milk of transgenic sheep," Bio/Technology, vol. 7, no. 5, pp. 487-492, 1989.

[12] K. E. van Cott, S. P. Butler, C. G. Russell et al., "Transgenic pigs as bioreactors: a comparison of gamma-carboxylation of glutamic acid in recombinant human protein $\mathrm{C}$ and factor IX by the mammary gland," Genetic Analysis, vol. 15, no. 3-5, pp. 155-160, 1999.

[13] M. Lindsay, G.-C. Gil, A. Cadiz, W. H. Velander, C. Zhang, and K. E. van Cott, "Purification of recombinant DNA-derived factor IX produced in transgenic pig milk and fractionation of active and inactive subpopulations," Journal of Chromatography A, vol. 1026, no. 1-2, pp. 149-157, 2004.

[14] S. C. Wu, Generation and analysis of transgenic mice and pigs harboring aLA-pLF and/or aLA-hFIX gene(s) [Ph.D. thesis], National Taiwan University, Taipei, Taiwan, 1998.

[15] K. H. Choo, K. Raphael, W. McAdam, and M. G. Peterson, "Expression of active human blood clotting factor IX in transgenic mice: use of a cDNA with complete mRNA sequence," Nucleic Acids Research, vol. 15, no. 3, pp. 871-884, 1987.

[16] S. R. Wang, T. Y. Lin, C. M. Chen, and C. N. Weng, "Isolation and expression of a porcine lactoferrin gene," American Journal of Veterinary Research, vol. 58, no. 10, pp. 1152-1158, 1997.

[17] S. C. Wu, T. K. Cheng, C. M. Chen, S. P. Lin, C. H. Yen, and P. C. Yang, "Method for expressing multiple recombinant proteins in milk of transgenic non-human mammals," US. Patent 7,087,808, 2006.

[18] R. K. Merkle and I. Poppe, "Carbohydrate composition analysis of glycoconjugates by gas-liquid chromatography/mass spectrometry," Methods in Enzymology, vol. 230, pp. 1-15, 1994.

[19] P. A. Price, "Analysis for $\gamma$-carboxyglutamic acid," Methods in Enzymology, vol. 91, pp. 13-17, 1983.

[20] C.-H. Yen, C.-K. Yang, I.-C. Chen et al., "Expression of recombinant Hirudin in transgenic mice milk driven by the goat $\beta$ casein promoter," Biotechnology Journal, vol. 3, no. 8, pp. 10671077, 2008.

[21] H. Atoda, E. Yokota, and T. Morita, "Characterization of a monoclonal antibody $\mathrm{B} 1$ that recognizes phosphorylated ser-158 in the activation peptide region of human coagulation factor IX," The Journal of Biological Chemistry, vol. 281, no. 14, pp. 9314-9320, 2006.

[22] V. Vetri, R. Carrotta, P. Picone, M. di Carlo, and V. Militello, "Concanavalin A aggregation and toxicity on cell cultures," Biochimica et Biophysica Acta, vol. 1804, no. 1, pp. 173-183, 2010.

[23] G. C. White II, A. Beebe, and B. Nielsen, "Recombinant factor IX," Thrombosis and Haemostasis, vol. 78, no. 1, pp. 261-265, 1997.

[24] M. Bond, M. Jankowski, H. Patel et al., "Biochemical characterization of recombinant factor IX," Seminars in Hematology, vol. 35, no. 2, pp. 11-17, 1998.

[25] M.-C. Poon, D. Lillicrap, C. Hensman, R. Card, and M.-F. Scully, "Recombinant factor IX recovery and inhibitor safety: a Canadian post-licensure surveillance study," Thrombosis and Haemostasis, vol. 87, no. 3, pp. 431-435, 2002.

[26] K. W. Hallgren, W. Qian, A. V. Yakubenko, K. W. Runge, and K. L. Berkner, "r-VKORC1 expression in factor IX BHK cells increases the extent of factor IX carboxylation but is limited by saturation of another carboxylation component or by a shift in the rate-limiting step," Biochemistry, vol. 45, no. 17, pp. 55875598, 2006.

[27] S. W. Pipe, "Recombinant clotting factors," Thrombosis and Haemostasis, vol. 99, no. 5, pp. 840-850, 2008.

[28] K. Bork, R. Horstkorte, and W. Weidemann, "Increasing the sialylation of therapeutic glycoproteins: the potential of the sialic acid biosynthetic pathway," Journal of Pharmaceutical Sciences, vol. 98, no. 10, pp. 3499-3508, 2009.

[29] E. G. Lee, S. H. Lee, K. M. Park et al., "Purification and characterization of recombinant human erythropoietin from milk of transgenic pigs," Journal of Chemical Technology \& Biotechnology, vol. 84, no. 5, pp. 643-649, 2009.

[30] T. Edmunds, S. M. van Patten, J. Pollock et al., “Transgenicaily produced human antithrombin: structural and functional comparison to human plasma-derived antithrombin," Blood, vol. 91, no. 12, pp. 4561-4571, 1998.

[31] P. H. C. van Berkel, M. M. Welling, M. Geerts et al., "Large scale production of recombinant human lactoferrin in the milk of transgenic cows," Nature Biotechnology, vol. 20, no. 5, pp. 484487, 2002.

[32] G.-C. Gil, W. H. Velander, and K. E. van Cott, "Analysis of the N-glycans of recombinant human Factor IX purified from transgenic pig milk," Glycobiology, vol. 18, no. 7, pp. 526-539, 2008.

[33] J. C. Keith Jr., T. J. Ferranti, B. Misra et al., "Evaluation of recombinant human factor IX: pharmaco kinetic studies in the rat and the dog," Thrombosis and Haemostasis, vol. 73, no. 1, pp. 101-105, 1995.

[34] C.-H. Chang, T.-K. Chou, C.-Y. Yang, T.-J. Chang, Y.-H. $\mathrm{Wu}$, and T.-W. Lee, "Biodistribution and pharmacokinetics of transgenic pig-produced recombinant human factor IX (rhFIX) in rats," In Vivo, vol. 22, no. 6, pp. 693-697, 2008. 


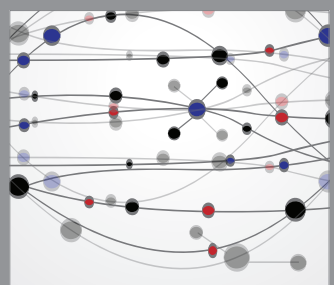

The Scientific World Journal
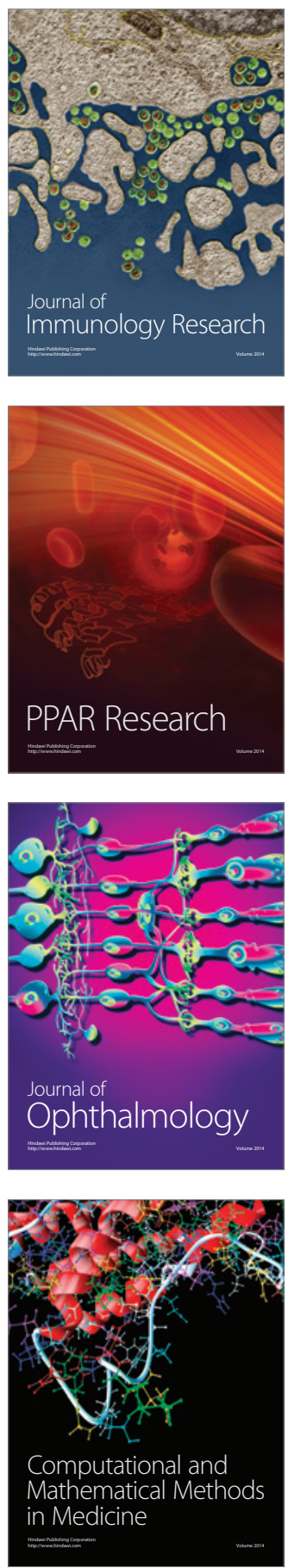

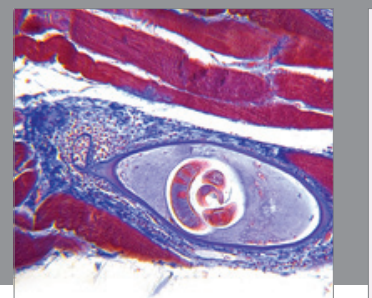

Gastroenterology

Research and Practice
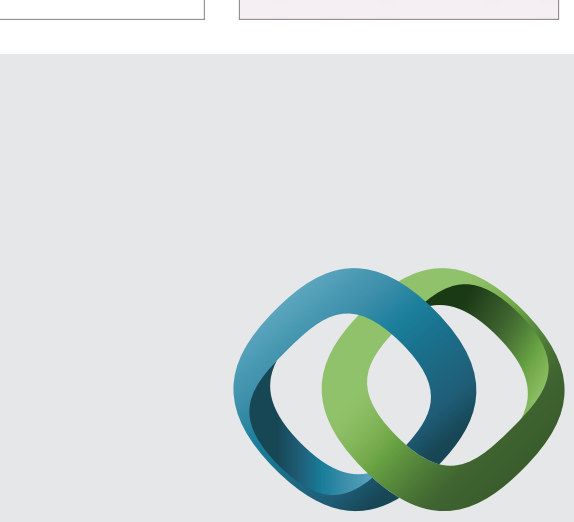

\section{Hindawi}

Submit your manuscripts at

http://www.hindawi.com
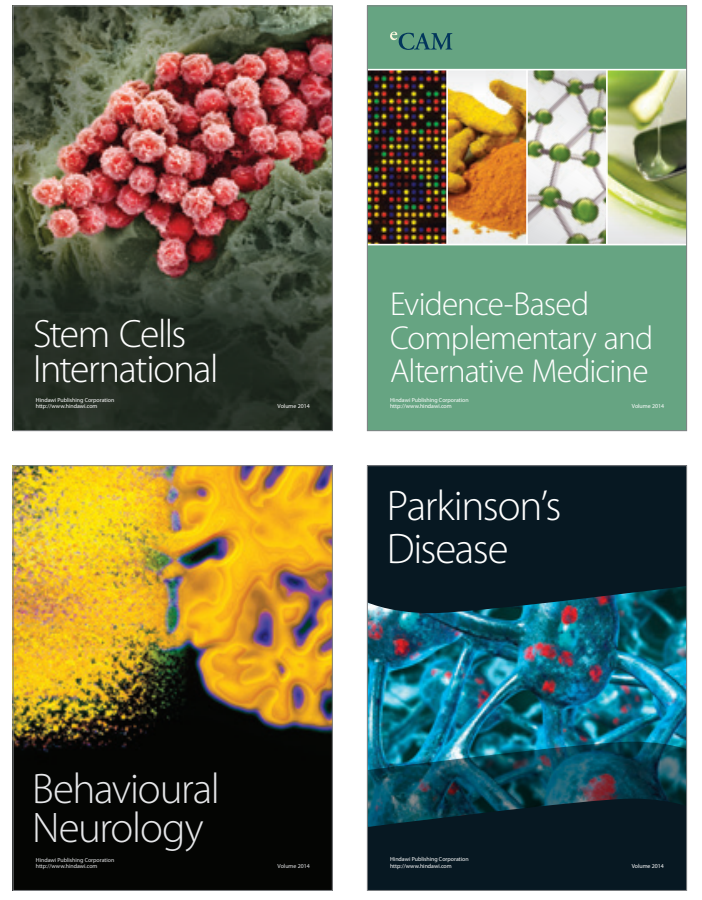
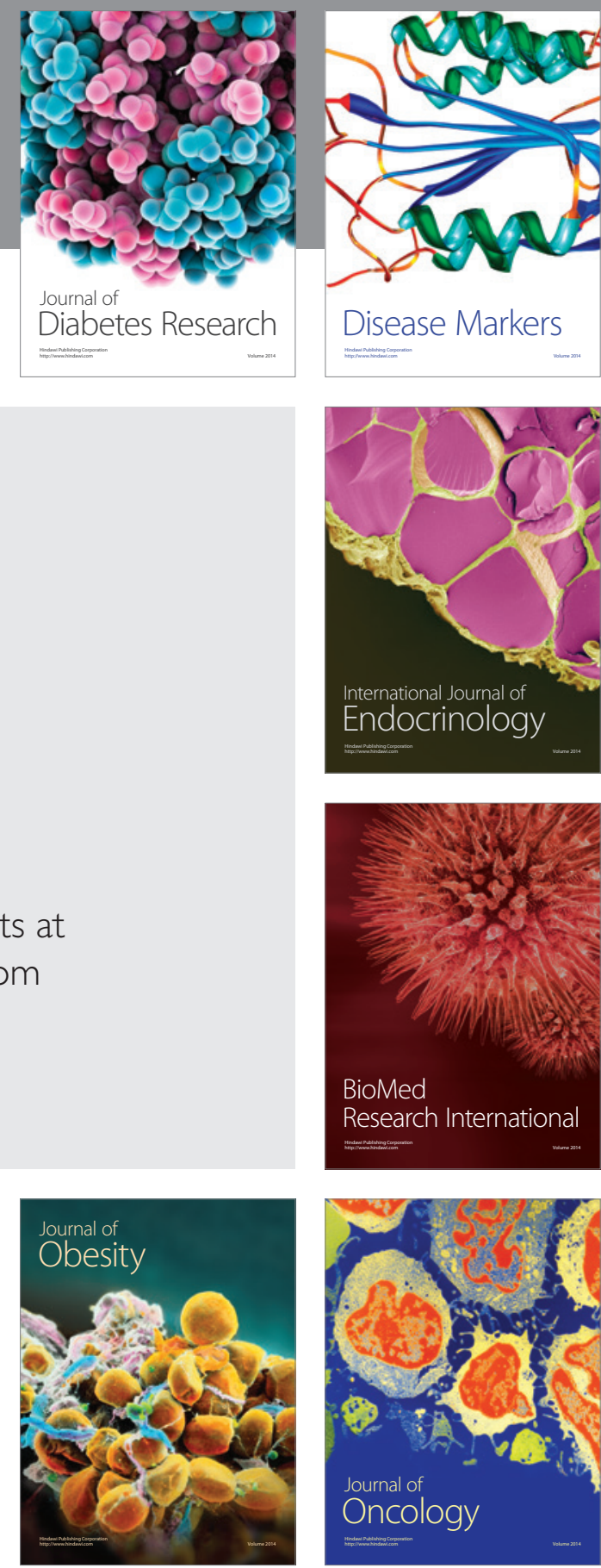

Disease Markers
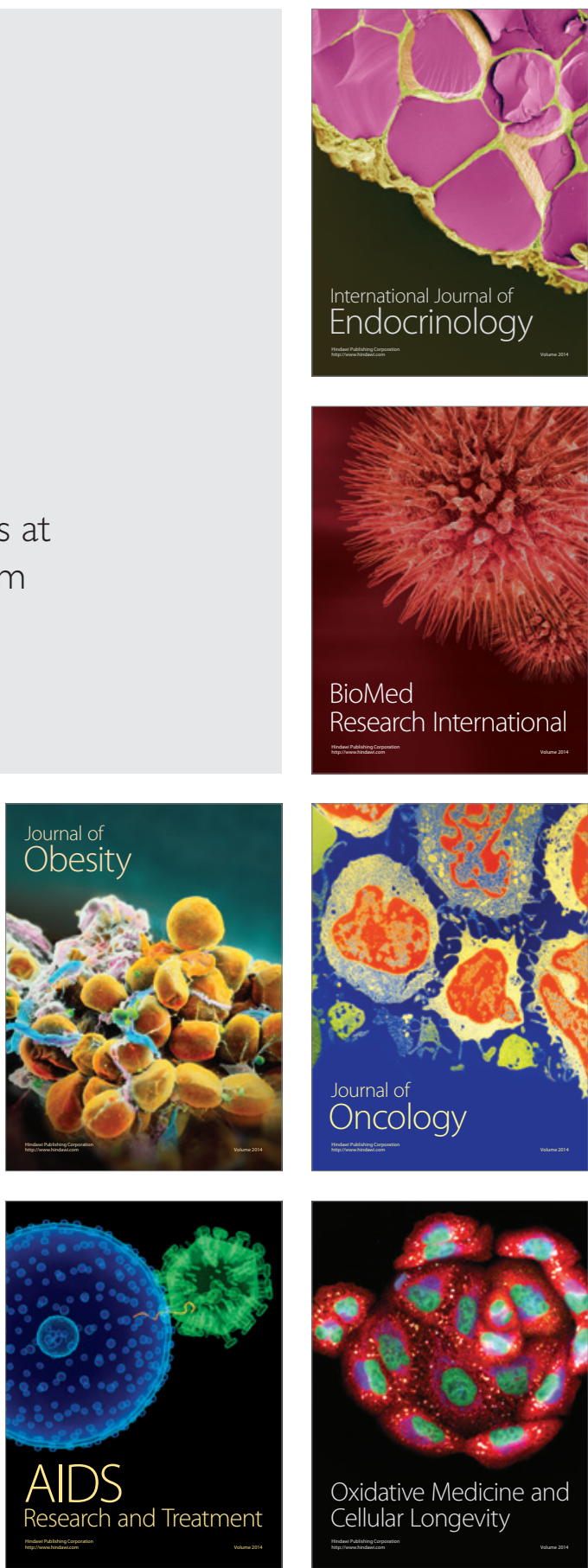